Myers, D. K. (1950). Arch. Biochem. 27, 341.

Myers, D. K. (1952a). Biochem. J. 51, 303.

Myers, D. K. (1952b). Arch. Biochem. Biophys. 37, 469.

Myers, D. K. (1952c). Science, 115, 568.

Myers, D. K. \& Mendel, B. (1949). Proc. Soc. exp. Biol., N.Y., 71, 357.

Myers, D. K. \& Mendel, B. (1952). 2nd Int. Congr. Biochem. Abstr. p. 248.

Nachmansohn, D. \& Feld, E. A. (1947). J. biol. Chem. 171, 715.

Nachmansohn, D. \& Rothenberg, M. A. (1945). J. biol. Chem. 158, 653.

Ord, M. G. \& Thompson, R. H. S. (1950). Biochem. J. 46, 346.

Ord, M. G. \& Thompson, R. H. S. (1951). Biochem. J. 49, 191.
Ord, M. G. \& Thompson, R. H. S. (1952). Biochem. J. 51, 245.

Sawyer, C. H. (1945). Science, 101, 385.

Sawyer, C. H. \& Everett, J. W. (1947). Amer. J. Physiol. 148, 675.

Smith, E. L. (1951). In Enzymes and Enzyme Systems, p. 47. Cambridge, Mass., U.S.A.: Harvard University Press.

Sturge, L. M. \& Whittaker, V. P. (1950). Biochem. J. 47, 518.

Thompson, R. H. S. \& Whittaker, V. P. (1944). Biochem. J. 38, 295.

Whittaker, V. P. (1949). Biochem. J. 44, xlvi.

Whittaker, V. P. (1951). Physiol. Rev. 81, 312.

Wright, 0. M. (1946). Studies on the Cholinesterase of Heart. M.A. Thesis, University of Toronto, Toronto, Canada.

\title{
An Apparatus for the Spectrokinetic Study of Rapid Reactions
}

\author{
BY K. DALZIEL \\ Department of Biochemistry (Radcliffe Infirmary), University of Oxford
}

\section{(Received 19 November 1952)}

The kinetic study of any chemical reaction requires the creation of a homogeneous, reacting mixture accessible to analysis at any instant during the change. For rapid reactions, this technical problem was first solved in a direct and general manner by Hartridge \& Roughton (1923). Their method was based on the constant flow principle: the reactants were driven at high speed through separate jets into a small chamber, where rapid mixing occurred. The reacting mixture flowed thence at constant rate down a tube of uniform bore, and could be analysed by optical or other physical means at any distance along the tube. Originally the analysis was made with a reversion spectroscope; later thermal and photoelectric methods were used (Roughton, 1930; Bateman \& Roughton, 1935; Roughton \& Millikan, 1936). The validity of the technique was established by various controls (Hartridge \& Roughton, 1923; Roughton \& Millikan, 1936).

Modifications of the method were devised by Millikan and by Chance, with rather different aims in view. In order to extend the work of Hartridge and Roughton on sheep hremoglobin to other oxygen-carrying pigments, Millikan (1936) adapted the constant-flow apparatus to the use of small quantities of material, by replacing the original gaspressure drive with motor-driven syringes and using a sensitive differential photoelectric colorimeter to analyse the flowing mixture. The apparatus of Chance $(1940,1951)$ was designed for the kinetic study of enzyme reactions and embodied fundamental alterations in technique. The requisite extension of the time range and economy of material were secured with an accelerated flow method and a very sensitive reaction meter with a high speed of response: a manual syringe drive gave an initial impetus to the reactants; and the subsequent variations of flow velocity, and therefore of time nterval, and the corresponding variations in the extent of reaction, measured photoelectrically at a fixed distance from the mixing chamber, were continuously recorded with a double-beam cathoderay tube. The complete kinetic curve was obtained directly as a trace, which could be photographed.

A modification of the Hartridge-Roughton apparatus, constructed for kinetic studies of human haemoglobin with precision as the major objective of the design, is described in this peper. The apparatus consists essentially of a constant-flow apparatus of the gas-pressure type and a photoelectric spectrophotometer (Beckman quartz Model DU), and can be used to record the absorption spectra of transient intermediate compounds (Dalziel \& O'Brien, 1951, 1952a, b). 


\section{DESIGN AND USE OF THE APPARATUS}

\section{Construction}

General features. The apparatus is shown diagrammatically in Fig. 1. The reactants are stored at constant temperature in vessels surrounded by water in a lagged pressure chamber, and are forced through capillary jets into the observation tube, which can be moved back and forth in the light beam from the spectrophotometer. Slower reactions are followed in a water-jacketed extension to the observation tube, after the flow has been stopped.
Reactant vessels and propulsion. The four 11 . glass reactant vessels, anchored by studs fixed on to the glass and bearing upwards on a heavy metal stand, are connected by glass siphon tubes and rubber junctions to outlets in the wall of the pressure chamber. The four outlets are glass tubes cemented into metal sleeves, and lead to two spring-loaded three-way glass stopcocks, and thence to the two jets. The stopcocks permit alternate flow of the reacting mixture and calibration fluids. The stopcock barrels are 1 in. diameter by $1 \frac{1}{2}$ in. length, and if carefully made and greased with Apiezon $\mathrm{L}$ will contain pressures of up to $50 \mathrm{lb}$./sq.in: They are clamped to a vertical plate screwed to the angle piece

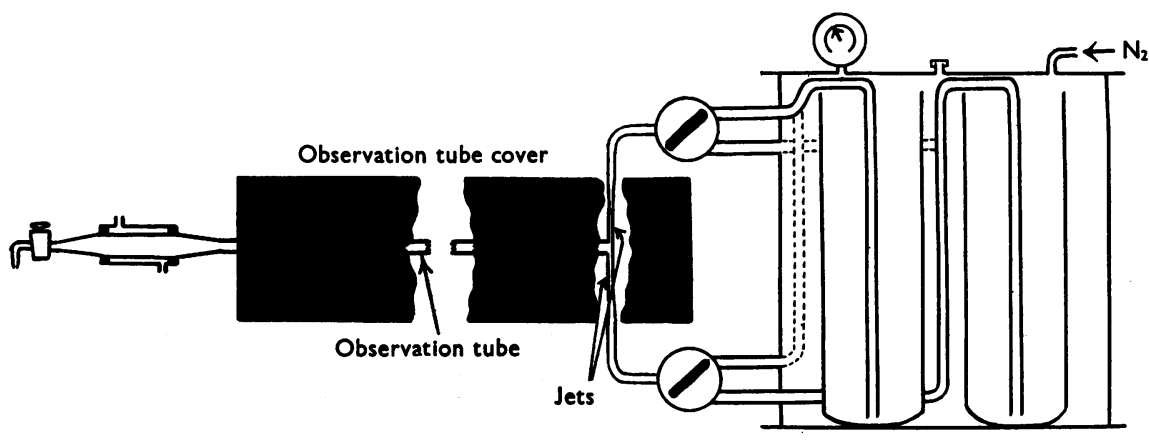

Pressure chamber

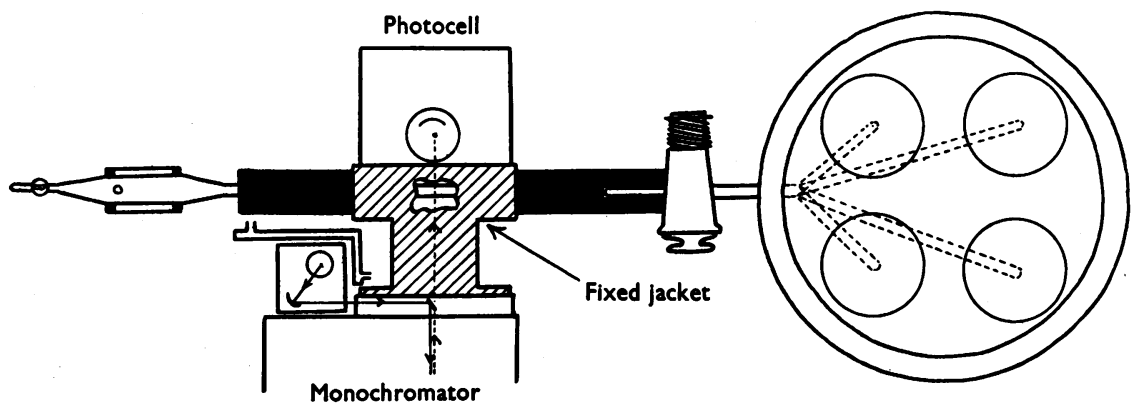

Fig. 1. Diagram of apparatus (not to scale).

Framework. The apparatus must be rigid, and the movement of the observation tube in the light path smooth and reproducible. The entire constant-flow apparatus is permanently mounted on a substage which travels along one limb of an L-shaped table, and the spectrophotometer is put in place on the other limb (Pl. la). A rectangular block containing the observation tube moves through a fixed metal jacket which replaces the cell compartment of the spectrophotometer, and about which the spectrophotometer may be assembled when required. The distance between two points of observation is read off on a scale suitably placed to indicate the distance travelled by the substage. The table top of $\frac{1}{2}$ in. bakelite is screwed to a steel frame supported by metal tubing. The substage, $\frac{3}{8}$ in. steel plate, runs on four wheels along two $\frac{7}{8}$ in. diameter steel rails screwed to the table, and the movement is controlled by a screw drive. which holds the jet-observation tube unit. The rubber connexions are either canvas reinforced or pressure tubing with clamps, and are wired on and sealed to the glass with Bostik C. The pressure tank is $\frac{8}{8}$ in. welded steel, $10 \mathrm{in}$. diam. by $10 \mathrm{in}$. high, tested hydraulically to $120 \mathrm{lb} . / \mathrm{sq} . \mathrm{in}$. Pressure is applied from a nitrogen cylinder through a reducing valve and a 60 l. tank which acts as a pressure stabilizer.

Jets, mixing chamber and observation tube. These parts (Fig. 2) are assembled as a single unit enclosed in a flat rectangular metal block (the observation tube cover) with a longitudinal slit through which measurements may be made right up to the mixing chamber without interference by external light. This arrangement is facilitated by a simple jet-mixing chamber unit, made by drilling into the wall of a glass capillary tube, first with a fine drill until the tip just enters the capillary, and then with a cylindrical grinding 

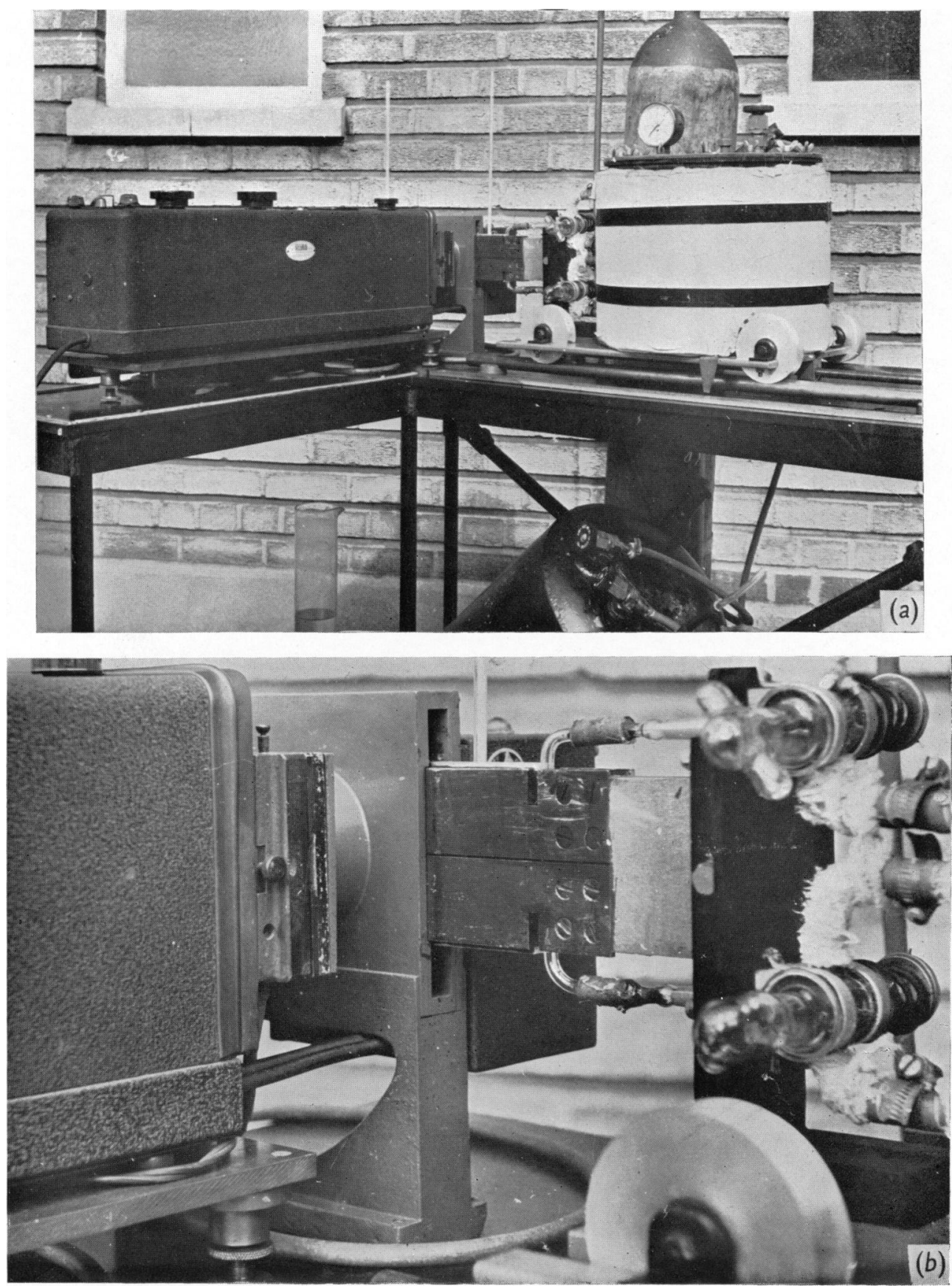

The rapid reaction apparatus. (a) Complete assembly. (b) Detail of spectrophotometer assembly.

K. DALZILL-AN APPARATUS FOR THE SPECTROKINETIC STUDY OF RAPID REACTIONS 
tool. Thus, two opposed jets open into the end of a cylindrical mixing chamber 2-3 mm. long. The observation tube, a $30 \mathrm{~cm}$. length of Veridia precision-bore glass tubing (Chance Bros. Ltd.) ground at the end to fit the curved surface of the jet unit, is cemented over the mixing chamber with Araldite (Aero Research Ltd.). To interchange jets and observation tubes of various dimensions, this joint can be severed by burning the cement. For studies of the deoxygenation of haemoglobin and the dehydration of carbonic acid, reactions with half periods of about 0.05 sec., the following dimensions proved convenient: jets $2.5 \mathrm{~cm}$. long and $0.5-1 \mathrm{~mm}$. diameter, mixing chamber 1-2 mm. diameter, and observation tube $2 \mathrm{~mm}$. diameter.

$$
\frac{\mathrm{cos}_{1.23}^{0.123}}{\mathrm{~cm}}
$$
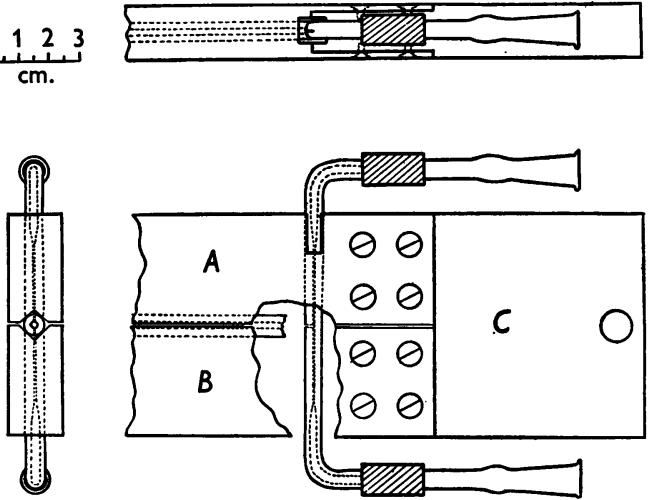

Fig. 2. Jets, observation tube and observation tube cover assembled.

The observation tube cover consists of three blocks of dural, painted flat black to reduce reflexion. To ensure that all light reaching the photocell passes through the reaction mixture, the observation tube is held rigidly between two of the blocks, $A$ and $B$, in V-shaped grooves, accurately milled to leave a uniform aperture of $1 \mathrm{~mm}$. along the length of the cover, inside which the $2 \mathrm{~mm}$. bore tube is aligned with its axis along the centre of the aperture. The third block, $C$, completes the enclosure of the jets, and is clamped in a slot in a heavy angle piece screwed to the substage. The jets are connected to the stopcocks by canvas-rubber junctions and ground-glass joints sealed with Chadwick's wax, which permit detachment of the complete jet-observation tube unit from the rest of the constant-flow apparatus.

Spectrophotometer assembly. The observation tube cover travels through a close-fitting brass jacket, fixed to the table, with clearance for the jet leads to permit observations up to the mixing chamber (Pl. 1b). The Beckman monochromator and photocell box are assembled around the jacket by means of screws and alignment pins, and the dimensions are such as to allow travel of the observation tube past the lamp house and its water cooler (Fig. 1). An adjustable vertical slit inside the jacket defines the length of the observation tube illuminated.

\section{Methods OF OPERATION}

It will be assumed that only one of the two reactants, reactant $R$, is coloured, in which case the absorption spectrum of the reaction mixture at the instant of mixing will be that of reactant $R$ appropriately

Biochem. 1953, 55 diluted with solvent. To record the changes of spectral absorption accompanying the reaction, two of the reactant vessels are filled with the reactants and the other two with solvent, so arranged that each jet will deliver either a reactant or solvent. The extinction of the reaction mixture, $E_{M}$, for light of a particular wavelength is determined at intervals during the reaction by measurements on the flowing mixture at various distances from the mixing chamber. Small differences between the optical depth at the several points of observation are corrected for by parallel measurements on $R$ mixed with solvent. The procedure at each point of observation is : (1) with both jets delivering solvent, the spectrophotometer is set to $E=0$ in the usual way, (2) reactant $R$ and solvent are run together, and the extinction $E_{R}=E_{M_{0}}$ recorded, (3) with both reactants running together, $E_{\boldsymbol{M}_{t}}$ is measured, and finally (4) solvent is run from both jets and the zero checked. The time $t$ is calculated from the distance of the point of observation from the mixing chamber, the cross-sectional area of the observation tube, and the measured volume flow rate. For measurements at times greater than 2 or 3 sec., the flow is stopped abruptly by closing the stopcock at the end of the observation tube, and the time course of the extinction is followed with a stop-watch.

The plot of $E_{M_{t}}$ against $t$ may be called a spectrokinetic curve for the reaction, and from the curves for a number of wavelengths the absorption spectrum of the reaction mixture can be built up at any stage of the reaction. Consecutive reactions may be indicated by simultaneous inflexions, maxima or minima in the spectrokinetic curves for several wavelengths, and the absorption spectrum of the mixture may permit characterization of the intermediate compounds (cf. Dalziel \& O'Brien, $1952 a$ ).

If the reaction is a simple one, in which $R$ is transformed directly into a single stable product $P$ by an isolated or reversible reaction, a series of absorption curves will be obtained intersecting at the isosbestic points of $R$ and $P$, and if Beer's law holds the spectrokinetic curve at an appropriate wavelength may be transposed into a concentrationtime curve. Consideration of the relationships involved, however, shows that more accurate kinetic measurements can be obtained by means of calibration fluids corresponding to 0 and $100 \%$ reaction (Appendix). The wavelength should be chosen according to the concentration of the initial reactant to give an extinction change of about 0.8 for the complete reaction. The calibration fluids are put in the reactant vessels which previously contained solvent, and the procedure for each measurement is: (1) the calibration fluid having the smaller extinction coefficient is run through the observation tube from one jet, and the spectrophotometer set to. 
$E=0$; (2) the other calibration fluid is run from the other jet, and the measured extinction is $\Delta E_{100 \%}$, the extinction change for complete reaction; (3) the reactants are run together and the extinction $\Delta E_{t}$ recorded; and finally (4) the zero setting is checked by repeating (1). Assuming that the $100 \%$ calibration fluid has the smaller extinction, then the concentration of reactant $R$ at time $t$, expressed as a fraction of the initial concentration, is $y=\Delta E_{t} /$ $\Delta E_{100 \%}$; the analysis is independent of the optical depth and of errors of the wavelength scale.

The calibration fluids are prepared beforehand by mixing resctant $R$ with solvent and with the second reactant. The correct proportions, which depend upon the relative delivery rates of the two jets, can be obtained by mixing the solutions in the apparatus, but transient fluctuations of the relative delivery rates, due to the passage of debris or stopcock grease, occasionally occur. The jets deliver at almost equal rates, and it is better to prepare the calibration fluids on this assumption, and to collect two or three samples of the reaction products from the apparatus during the experiment for comparison with the $100 \%$ calibration fluid in optical cells. Correction can then be made for small differences of concentration between the calibration fluids and the reaction mixture, and the initial reactant concentrations can be calculated.

\section{VALIDITY AND ACCURACY OF THE METHOD}

The performance of the component parts of the apparatus, and the factors upon which the validity and precision of the method depend will be considered individually.

\section{Mixing tests}

The efficiency of mixing was investigaiced by the thermal method of Hartridge \& Roughton (1924), which consists in mixing strong acid and base in the apparatus and measuring the increase of temperature of the flowing mixture, which is a measure of the extent of mixing, at various distances along the tube.

Copper-constantan needle thermocouples (Roughton \& Millikan, 1936) were used. The elements were enclosed in a steel tube, $0.7 \mathrm{~mm}$. external diameter, and the hot junction at one end of the tube was insulated and protected with an acid- and alkali-resistant bakelite varnish. The cold junctions, dipping into mercury contacts, were kept at constant temperature in a lagged vacuum-walled flask containing water at about room temperature. With a Cambridge 'spot' galvanometer of $400 \Omega$ resistance a deflexion of $1 \mathrm{~cm} .{ }^{\circ} \mathrm{C}$. was obtained. The mixing tests were made with approximately $2 \mathrm{~N}-\mathrm{NaOH}$ and $2 \mathrm{~N}-\mathrm{H}_{2} \mathrm{SO}_{4}$, the overall temperature increase being $13^{\circ}$. The concentrations were adjusted, according to the relative flow rates through the jets, to give exact neutralization in the apparatus, a condition essential to the validity of the method.
Results obtained with two-jet capillary mixing units of the type described earlier are summarized in Table 1 . With jets of 0.5 and $1 \mathrm{~mm}$. diameter, and mixing chambers of 1 and $2 \mathrm{~mm}$. diameter, mixing occurs to the extent of $90 \%$ or more in the mixing chamber and reaches $99 \%$ at a distance of $0.5-1 \mathrm{~cm}$. along the observation tube over a range of flow rates. The jets of smaller bore give the more rapid mixing: at a flow rate of about $140 \mathrm{~cm}$. $/ \mathrm{sec}$. down the observation tube, $99 \%$ mixing is achieved in 0.005 sec. with $0.5 \mathrm{~mm}$. jets, and in 0.008 sec. with $1 \mathrm{~mm}$. jets, whilst at the higher flow rate of $280 \mathrm{~cm}$./ sec., $1 \mathrm{~mm}$. jets also give $99 \%$ mixing in 0.005 sec.

Table 1. Efficiency of mixing with two-jet capillary units

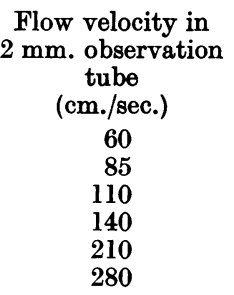

\begin{tabular}{cc} 
Time for $99 \%$ mixing (sec.) \\
\hline $0.5 \mathrm{~mm}$. jets & $1 \mathrm{~mm}$. jets \\
0.017 & - \\
0.008 & $\overline{-}$ \\
0.005 & 0.012 \\
- & 0.008 \\
- & 0.006 \\
& 0.005
\end{tabular}

Character of flow in the observation tube

The validity of the constant-flow method rests upon the assumption of an ideal type of flow in which all parts of the liquid move at the same rate down the observation tube. In practice, the velocity, and therefore the extent of reaction, will not be uniform over a cross-section. The observed extent of reaction at any distance along the tube will depend upon the radial velocity distribution and the way in which measurements are made; it will not be, in general, the true value corresponding to the mean time of arrival of the fluid at the crosssection, the time calculated from the measured volume flow rate.

Roughton \& Millikan (1936) showed theoretically that, with turbulent flow in the observation tube, errors from this source would be negligible, but with streamline flow, the observed percentage reaction might be up to $7 \%$ in error. They showed experimentally, however, that for flow rates theoretically in the streamline region (down to one-sixth of the critical velocity) the actual radial velocity distribution in the observation tube was much more uniform than for streamline flow, and calculated that the error of measurements of the percentage reaction would not normally exceed $0.8 \%$. These conclusions could not be assumed valid for the present apparatus, since the calculations involved an approximation justified only if the whole cross-section of the tube were illuminated and if the light absorption were very small (Millikan, 1932). The analysis has therefore been modified to cover the more general case. 
If only part of the cross-section of the observation tube is illuminated, the observed extent of reaction must lie somewhere between the values corresponding to the light absorption along a diameter and along the extreme chord. Calculations have been made, for streamline and turbulent flow, of the mean percentage reaction along each of these paths, for several assumed values of the true percentage reaction.

Method. Consider a cross-section of the observation tube, Fig. 3, and let $\bar{t}$ be the average time of arrival of the fluid at this cross-section; this will be the measured time for the cross-section in the constant-flow method, calculated from the volume flow rate, the distance from the mixing chamber,

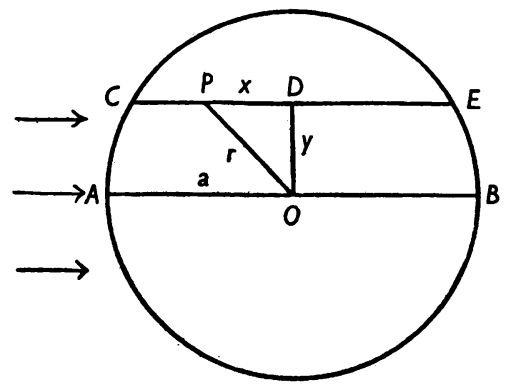

Fig. 3. Cross-section of the observation tube, for calculations on character of flow.

and the radius of the tube, $a$. Let $P$ be any point in the crosssection distance $r$ from the centre, and $C D E$ a chord through $P$ distance $y$ from the centre and parallel to the light. Then: (i) for a given radial velocity distribution (assumed to be set up at the mixing chamber) the time of arrival of the fluid at $P$ can be expressed in terms of $\bar{t}$ and $r$; (ii) for any assumed true extent of reaction in the measured time $\bar{t}$, the corresponding actual extent of reaction at $P$ can be expressed as a function of $r$; and (iii) the mean extent of reaction along the chord $C D E$ can be obtained by integration with respect to $x$, and would be the measured value if light were confined to this path.

(i) Time distribution over a cross-section. The velocity distribution for turbulent flow is given by $v=1 \cdot 225 \bar{v}(1-r / a)^{3}$ (Dodge \& Thompson, 1937), where $\bar{v}$ is the average velocity calculated from the volume flow rate. Hence the time of arrival of the fluid at $P$ is

$$
t=\frac{\bar{t}}{1 \cdot 225(1-r / a)^{\frac{1}{4}}} \text {. }
$$

Similarly, for streamline flow Poiseuille's equation gives

$$
t=\frac{\bar{t}}{2\left(1-r^{2} / a^{2}\right)} .
$$

(ii) Distribution of extent of reaction. The fraction of reaction, $f$, completed in time $t$ is, for a first-order reaction, $\left(1-e^{-k_{1} t}\right)$ and for a second-order reaction, $k_{2} b t /\left(1+k_{2} b t\right)$; $k_{1}, k_{2}$ are velocity constants, and in the second case $b$ is the initial concentration of the reactants. For ease of manipulation, choose arbitrary time units such that $t_{0 \cdot 5}=1$ in each case, whence $k_{1}=\ln 2$ and $k_{2} b=1$, and the above expressions may be replaced by

$$
\begin{aligned}
& \text { first order } \log (1-f)=-0 \cdot 301 t, \\
& \text { second order } \quad f=t / 1+t .
\end{aligned}
$$

Substitution for $t$ from ( 1$)$ and ( $1 a$ ) will give $f$ as a function of $\bar{t}$ and $r$ for turbulent and streamline flow, respectively, in the observation tube.

(iii) Mean extent of reaction along any chord. For a secondorder reaction with streamline flow, the fraction of reaction completed in an element of liquid at $P$ is, from (1 $a)$ and $(2 a)$,

$$
f=\frac{\bar{t}}{2\left\{1-\left(x^{2}+y^{2}\right) / a^{2}\right\}+t}=\phi(x) .
$$

The mean value of this function in the interval $x=0$ to $x=i$ is $i^{-1} \int_{0}^{i} \phi(x) \mathrm{d} x$, and when $i=\left(a^{2}-y^{2}\right)^{\frac{1}{2}}$, this will give the average extent of reaction along $C D$ (Fig. 3), and therefore, by symmetry, along the whole chord $C D E$. The solution is

$$
\begin{aligned}
\bar{f}=\frac{2 \cdot 3 \bar{t}}{4\left(1-y^{2} / a^{2}\right)^{\frac{1}{2}}\left(1-y^{2} / a^{2}+\bar{t} / 2\right)^{\frac{1}{3}}} \\
\qquad \log \frac{\left(1-y^{2} / a^{2}+\bar{t} / 2\right)^{\frac{1}{2}}+\left(1-y^{2} / a^{2}\right)^{\frac{1}{3}}}{\left(1-y^{2} / a^{2}+\bar{t} / 2\right)^{\frac{1}{2}}-\left(1-y^{2} / a^{2}\right)^{\frac{1}{3}}} .
\end{aligned}
$$

This equation gives the extent of reaction indicated by the light absorption along any chord distance $y$ from the axis, and can be evaluated for any values of $\bar{t}$ and $y / a$. The corresponding true values of $f$ are obtained by substituting $\bar{t}$ for $t$ in equation ( $2 a)$.

For turbulent flow or a first-order reaction, the above integration is more difficult, and arithmetic integration has been used (cf. Roughton \& Millikan, 1936). Suppose that fluid passing down the observation tube be divided into ten concentric cylindrical elements, and imagine that each element moves as a solid block. Let the elements be of equal thickness, so that the cross-section of the observation tube be divided into ten concentric areas having mean radii $a / 20$, $3 a / 20,5 a / 20, \ldots, 19 a / 20$. The time of arrival of each element at the cross-section of observation may be calculated from these mean radii in terms of $\bar{t}$, by equation (1) or (1 $a)$; and then from equation (2) or (2a) the mean extent of reaction in each element may be obtained in terms of $\bar{t}$. If now arbitrary values be given to $\bar{t}$, the corresponding actual extents of reaction in each element may be calculated. Finally, a given light path through the observation tube, along a chord of the cross-section, will pass through some or all of the ten elements, and the length of the path in each element may be calculated geometrically. If Beer's law be valid, the total extinction will be the sum of the extinctions for each element, and the measured percentage reaction along the chord will be the sum of ( $\%$ reaction $\times$ path length) for all the elements, divided by the total path length. For streamline flow and a second-order reaction, this method gives results in close agreement with those obtained from equation (3).

The results of such calculations for the two extreme light paths in the present apparatus, a diameter and a chord bisecting a radius, are given in Table 2. For a first-order reaction and with turbulent flow, these extreme values for the extent of reaction do not differ by more than $2.2 \%$. It may be assumed for the purposes of approximate calcu- 
Table 2. Calculated values for the observed extent of (1) a first-order reaction and (2) a second-order reaction with streamline and turbulent flow in the observation tube

(The limiting values are for imagınary light paths confined to a diameter and a chord bisecting a radius: see text.)

\begin{tabular}{|c|c|c|c|c|c|c|c|c|}
\hline \multirow{4}{*}{$\begin{array}{l}\text { True \% } \\
\text { reaction }\end{array}$} & \multicolumn{8}{|c|}{ Observed \% reaction } \\
\hline & \multicolumn{4}{|c|}{ Streamline flow } & \multicolumn{4}{|c|}{ Turbulent flow } \\
\hline & \multicolumn{2}{|c|}{ Limiting values } & \multirow[b]{2}{*}{ Mean } & \multirow[b]{2}{*}{ Error } & \multicolumn{2}{|c|}{ Limiting values } & \multirow[b]{2}{*}{ Mean } & \multirow[b]{2}{*}{ Error } \\
\hline & Diameter & Chord & & & Diameter & Chord & & \\
\hline \multicolumn{9}{|c|}{ (1) First-order reaction } \\
\hline $\begin{array}{l}12 \cdot 9 \\
29 \cdot 3 \\
50 \cdot 0 \\
75 \cdot 0 \\
87 \cdot 5\end{array}$ & $\begin{array}{l}14 \cdot 5 \\
29 \cdot 7 \\
46 \cdot 6 \\
67 \cdot 0 \\
78 \cdot 8\end{array}$ & $\begin{array}{l}18 \cdot 1 \\
\mathbf{3 6} \cdot 2 \\
55 \cdot 2 \\
76 \cdot 0 \\
\mathbf{8 6 \cdot 6}\end{array}$ & $\begin{array}{l}16 \cdot 3 \\
\mathbf{3 3 \cdot 0} \\
50 \cdot 9 \\
71 \cdot 5 \\
82 \cdot 7\end{array}$ & $\begin{array}{l}+3.4 \\
+3.7 \\
+0.9 \\
-3.5 \\
-4.8\end{array}$ & $\begin{array}{l}12 \cdot 2 \\
27 \cdot 8 \\
47 \cdot 6 \\
72 \cdot 3 \\
85 \cdot 3\end{array}$ & $\begin{array}{l}12 \cdot 8 \\
29 \cdot 1 \\
49 \cdot 6 \\
74 \cdot 5 \\
87 \cdot 0\end{array}$ & $\begin{array}{l}12 \cdot 5 \\
28 \cdot 5 \\
48 \cdot 6 \\
73 \cdot 4 \\
86 \cdot 2\end{array}$ & $\begin{array}{l}-0.4 \\
-0.8 \\
-1.4 \\
-1.6 \\
-1.3\end{array}$ \\
\hline \multicolumn{9}{|c|}{ (2) Second-order reaction } \\
\hline $\begin{array}{r}9 \cdot 1 \\
33 \cdot 3 \\
50 \cdot 0 \\
66 \cdot 6 \\
80 \cdot 0\end{array}$ & $\begin{array}{l}10 \cdot 0 \\
32 \cdot 0 \\
46 \cdot 6 \\
62 \cdot 3 \\
76 \cdot 0\end{array}$ & $\begin{array}{l}12 \cdot 4 \\
37 \cdot 9 \\
53 \cdot 6 \\
68 \cdot 6 \\
80.9\end{array}$ & $\begin{array}{l}11 \cdot 2 \\
35 \cdot 0 \\
50 \cdot 1 \\
65 \cdot 5 \\
78 \cdot 5\end{array}$ & $\begin{array}{l}+2.1 \\
+1.7 \\
+0.1 \\
-1.1 \\
-1.5\end{array}$ & $\begin{array}{r}8 \cdot 6 \\
31 \cdot 8 \\
48 \cdot 2 \\
65 \cdot 0 \\
78 \cdot 7\end{array}$ & $\begin{array}{r}9 \cdot 0 \\
33 \cdot 1 \\
49 \cdot 8 \\
66 \cdot 4 \\
80 \cdot 7\end{array}$ & $\begin{array}{r}8 \cdot 8 \\
32 \cdot 5 \\
49 \cdot 0 \\
65 \cdot 7 \\
79 \cdot 7\end{array}$ & $\begin{array}{l}-0.2 \\
-0.8 \\
-1.0 \\
-0.9 \\
-0.3\end{array}$ \\
\hline
\end{tabular}

lation that the reaction mixture is illuminated by a parallel beam of light of uniform intensity, in which case the observed percentage reaction should be close to the mean of these extreme values. The data of Table 2 show that for turbulent flow the maximum error calculated in this way is $-1.6 \%$. For streamline flow, the discrepancies are greater, and are in opposite senses in the early and late stages of the reaction. For a second-order reaction, the calculated errors are somewhat smaller, the maximum values being $+2 \%$ and $-1 \%$ for streamline and turbulent flow, respectively. It should be emphasized that these calculated errors are probably overestimates, since they are derived on the assumption that the characteristic velocity distribution is set up at the entrance to the observation tube, whereas in practice mass flow prevails near the inlet and only gradually gives way to the typical distribution.

It is concluded that with turbulent flow in the observation tube, the method will give valid results, but with streamline flow significant discrepancies might occur, especially with a first-order reaction. These conclusions have been tested to some extent experimentally by comparing kinetic measurements at flow rates above and below the critical velocity (cf. Hartridge \& Roughton, 1923), as described later.

\section{Rate and stability of flow}

The constancy of the flow rate, which determines the precision of the time measurements, was tested in 'dummy' kinetic experiments with a rotameter and by repeated measurements of the volume of fluid delivered in a measured time. With $0.5 \mathrm{~mm}$. jets, flow rates of from 3 to $7 \mathrm{ml} . / \mathrm{sec}$. were obtained in the pressure range $10-40 \mathrm{lb}$./sq.in. During flow from a single jet, the rotameter readings were quite steady, but with both jets delivering fluid together the readings fluctuated quite rapidly over a range of $\pm 1 \%$. The flow rates calculated from the volume of fluid delivered in periods of $10 \mathrm{sec}$. or more were constant during an experiment to within $\pm 1 \%$. The upper limit to the flow rate with this jet unit, however, was set at about $5 \mathrm{ml}$./sec. by the onset of cavitation of flow in the jets, accompanied by noise, slight turbidity and often by a sudden change of the relative rates of delivery through the jets. With $1 \mathrm{~mm}$. jets, the flow was apparently more stable. The rotameter readings were constant to within $\pm 0 \cdot 2 \%$, and the measured volume flow rate to less than $\pm 0.5 \%$. Cavitation in the jets began at about $15 \mathrm{ml}$./sec. with a driving pressure of 40 lb./sq.in.

Fluctuations of the relative delivery rates, a possible source of error in the concentration measurements, were tested by mixing $2 \mathrm{~N}-\mathrm{H}_{2} \mathrm{SO}_{4}$ and $2 \mathrm{~N}-\mathrm{NaOH}$ in the apparatus, and titrating the excess acid or alkali in small samples of the runnings. With both 0.5 and $1 \mathrm{~mm}$. jets, the average relative deliveries for periods of 0.5 sec. and longer did not vary by more than $\pm 0.3 \%$ during an experiment.

The slight pulsation of flow indicated by the rotameter was confirmed by vibration of the Beckman galvanometer needle during extinction measurements on a flowing reaction mixture. Similar but smaller variations of extinction reading in absence of any reaction, that is when inert coloured and colourless fluids were mixed in the apparatus, showed that the relative delivery rates also oscillate rapidly over a small range of values. With $0.5 \mathrm{~mm}$. jets, the galvanometer fluctuations did not seriously affect the precision of the measurements (at minimum Beckman sensitivity), as shown by the agreement between duplicate measurements, and it is estimated that the mean extinction reading is subject to an error corresponding to a variation of $\pm 0.5 \%$ in the relative delivery rates. With $1 \mathrm{~mm}$. 
jets, the instability was more serious, but it was found possible to reduce it by putting a short length of capillary tube at the entrance to the siphon tube in each reactant vessel. With $2.5 \mathrm{~cm}$. lengths of $1 \mathrm{~mm}$. diameter capillary, the galvanometer fluctuations were no greater than with a $0.5 \mathrm{~mm}$. jet unit, and for driving pressures of 10-40 lb./sq.in. the flow-rate range was 5-12 ml./ sec. With $1.27 \mathrm{~cm}$. lengths of $0.5 \mathrm{~mm}$. capillaries, the galvanometer fluctuations were almost negligible, and the flow-rate range within the same pressure limits was $2 \cdot 5-5 \mathrm{ml}$./sec. The additional resistance to flow is an advantage for work at low flow rates, since the effect of small pressure changes on the flow rate is least at high pressures.

\section{Measurement of concentration}

The applicability of Beer's Law. Extinction measurements in a cylindrical tube are liable to errors of two sorts, manifest as apparent deviations from Beer's Law in the form $\log I_{0} / I_{t}=k c d$. First, the light path involves refraction, and the amount of light reaching the photocell may change with the refractive index of the solution, and therefore with solute concentration, independently of any absorption. Secondly, different parts of the light beam will traverse different depths of solution, and since $I_{t}$, the intensity of the transmitted light, is an exponential function of the product $c d, \log I_{0} / I_{t}$ will not be a linear function of $c$. To minimize such deviations, the observation tube cover was so designed that light can pass only through the middle part of the cross-section of the tube: an approximately parallel light beam from the monochromator falls normally on the $1 \mathrm{~mm}$. slit in the cover, and the observation tube, external diameter $7 \mathrm{~mm}$. and internal diameter $2 \mathrm{~mm}$., is accurately aligned with its axis along the centre of the slit. With water in the observation tube, the light transmission varied by $\pm 5 \%$ over the length of the tube. Geometrically, the longest and shortest possible light paths through the tube differ by $15 \%$, and refraction should be quite small.

The applicability of Beer's law to measurements in the tube was tested with oxyhaemoglobin solutions, which are known to obey the Beer-Lambert law up to high concentrations (Drabkin \& Austin, 1935-6). Within the instrumental error, the relation between extinction and concentration was linear up to $E=1 \cdot 0-1 \cdot 5$ at $415,430,465,540$ and $560 \mathrm{~m} \mu$., and the effective optical depth was constant to within $1 \%$ over the length of the tube. Similar results were obtained in a $10 \mathrm{~mm}$. bore tube with a $5 \mathrm{~mm}$. aperture, which is used for stopped flow measurements. So far as errors due to non-uniform optical depth are concerned, these results should be of general validity for the stated geometrical conditions.

The existence of refraction effects was shown by a greater light transmission with solutions of colourless inorganic salts in the observation tube than with water. The transmission increments for $0.1 \mathrm{M}$ solutions were about $0.5 \%$, equivalent to an extinction of -0.002 , and increased with concentration. Kinetic measurements would not be significantly affected except at rather high reactant concentrations, and then chiefly through the difference in total solute concentration between the reactant mixture and the ' unreacted' calibration fluid, which lacks one reactant. This could be compensated by an inert solute.

Slit length error. The measured extent of reaction at a given distance from the mixing chamber is really an average value for a small but finite length of the observation tube (the slit length), equivalent to a finite time interval, and for non-linear kinetic curves differs from the actual value at the measured time, the time corresponding to the centre of the slit. Chance (1940) showed that the error depends upon the ratio of slit length to distance from the mixing chamber, and on the stage of the reaction. It is not a limiting factor in the present apparatus : a slit length of only $0.5 \mathrm{~mm}$. gives enough light for measurement, and both calculation and experiment (see later) show that the slit length can be increased to $5 \mathrm{~mm}$. without affecting the results. With a slit length of $2 \mathrm{~mm}$., a spectral band width of $5 \mathrm{~m} \mu$. is required at a wavelength of $430 \mathrm{~m} \mu$.

Optimum wavelength. The factors which determine the accuracy of the concentration measurements are discussed in the Appendix. The relative magnitudes of the molar extinction coefficients of reactant and product, $\epsilon_{R}$ and $\epsilon_{P}$ respectively, at the wavelength chosen for measurements are shown to affect the accuracy in three ways: (1) the precision of the measurements depends upon the magnitude of $\Delta E_{100 \%}=C_{o} d\left(\epsilon_{R} \sim \epsilon_{P}\right)$, the extinction change for complete reaction, and the wavelength should be chosen with regard to the initial reactant concentration, $C_{o}$, and the optical depth, $d$, to give the optimum value of $\Delta E_{100 \%}=0.8 ;(2)$ the variation of the proportional error with the reactant concentration, $C_{t}$, depends upon the sign of $\left(\epsilon_{R} \sim \epsilon_{P}\right)$, and is least when $\epsilon_{R}>\epsilon_{P}$, although smaller errors are obtained over the first half of the reaction when $\epsilon_{P}>\epsilon_{R}$; (3) errors due to uncertainties in the relative delivery rates increase with the ratio, $r$, of the smaller extinction coefficient to the difference between them, and are minimal when the wavelength is such that either $\epsilon_{R}$ or $\epsilon_{P}$ is zero.

Accuracy. With a Beckman spectrophotometer at minimum sensitivity, and the optimum value of $\Delta E_{100 \%}=0.8$, the fractional composition of the mixture can be determined to within $\pm 1 \% C_{o}$ or less at all stages of the reaction, so far as the precision of the spectrophotometer is concerned. Over the range $\Delta E_{100 \%}=0 \cdot 2-1 \cdot 2$, the maximum error is $1.6 \% C_{o}$, so that at a given wavelength a sixfold variation of the initial reactant concentration is possible without significant loss of precision. These 
instrumental errors could be halved by working at maximum spectrophotometer sensitivity, but galvanometer fluctuations due to rapid oscillation of the relative delivery rates nullify the increased sensitivity except at low flow rates. The analytical error resulting from this flow instability depends upon the extinction coefficients of reactant and product (Appendix).

In studying a first-order reaction, it is desirable that the absolute error in $\log y$ (where $y=C_{t} / C_{o}$ ), and therefore the proportional error in $y$, be independent of $y$. This is most closely approached when $\epsilon_{R}>\epsilon_{P}$; if $\epsilon_{P}$ is small, and $\Delta E_{100 \%}=0 \cdot 8$, it is estimated that the accuracy of the analysis will be $\pm 1.5 \% y$ over the first $70 \%$ of the reaction, and $\pm 2.5 \% y$ when reaction is $95 \%$ complete.

\section{Temperature control}

For work near room temperature, the temperature of the reactants remains quite constant in the lagged pressure chamber, and there is little heat exchange during flow through the lagged leads and the observation tube: if the air temperature is within about $1^{\circ}$ of the intial reactant temperature, the temperature of the fluids does not change by more than $0 \cdot 1^{\circ}$. For stopped-flow measurements, which might incur more serious temperature drifts, a water-jacketed extension to the observation tube is used. Thermostatic control has not yet been attempted, but for work above room temperature heating elements have been inserted in the observa. tion tube cover.

\section{THE KINETICS OF CARBONIC ACID DEHYDRATION}

The dehydration of carbonic acid has been investigated by several workers with various rapid reaction techniques, and serves as a convenient overall test of the present apparatus. Faurholt (1924) found that the kinetics of $\mathrm{H}_{2} \mathrm{CO}_{3} \rightarrow \mathrm{CO}_{2}+\mathrm{H}_{2} \mathrm{O}$ at $\mathrm{pH}<8$ could be described by

$$
\mathrm{d}\left[\mathrm{CO}_{2}\right] / \mathrm{d} t=k_{1}\left[\mathrm{H}_{2} \mathrm{CO}_{3}\right]-k_{2}\left[\mathrm{CO}_{2}\right] \text {. }
$$

Brinkman, Margaria \& Roughton (1933) showed that if the reaction is brought about in acid solution by mixing sodium bicarbonate and hydrochloric acid, this mechanism should give an approximately linear plot of $\mathrm{pH}$ against time, with a slope of $k_{1} / 2 \cdot 3$, and by colorimetric $\mathrm{pH}$ measurements in a rapid reaction apparatus, they confirmed Faurholt's conclusions and obtained a mean value of $k_{1}=12.9 \mathrm{sec}^{-1}$ at $18^{\circ}$, in satisfactory agreement with the results obtained by other methods (Roughton, 1936). The reaction has been studied under the same conditions with the present apparatus.

\section{EXPERTMENTAL}

Spectrophotometric measurements of $\mathrm{pH}$. Brode (1924) showed that the effect of $\mathrm{pH}$ upon the spectral absorption of several indicators is consistent with the existence of an acidbase equilibrium between two species possessing characteristic absorption spectra, and that $\mathrm{pH}$ can be determined accurately by spectrophotometric analysis.

If, for a given wavelength, optical depth and indicator concentration, $E_{A}$ and $E_{B}$ are respectively the extinctions of the pure acid and alkaline forms of the indicator (i.e. of calibration fluids of extreme $\mathrm{pH}$ ), and $E$ is the extinction of the test solution, then assuming that $E_{A}>E_{B}$, the ratio of the concentrations of the acid and alkaline forms of the indicator in the test solution is

$$
\left(E_{A}-E\right) /\left(E-E_{B}\right)=\left\{\left(E_{A}-E_{B}\right)-\left(E-E_{B}\right)\right\} /\left(E-E_{B}\right) .
$$

This ratio can be determined most precisely by direct measurement of the extinction differences

$$
\left(E_{A}-E_{B}\right)=\Delta E_{100 \%} \quad \text { and } \quad\left(E-E_{B}\right)=\Delta E \text { (Appendix). }
$$

$$
\text { Hence, } \quad \mathrm{pH}-\mathrm{p} K_{I n}=\log \frac{\Delta E_{100 \%}-\Delta E}{\Delta E},
$$

where $K_{I n}=$ indicator constant.

The validity of this equation for bromophenol blue was confirmed with Clarke \& Lubs phthalate-NaOH and phthalate-HCl buffers of known pH (Vogel, 1939). Potassium hydrogen phthalate, A.R., was dried for $2 \mathrm{hr}$. at $120^{\circ}$, and conc. $\mathrm{NaOH}$ solution made from A.R. sticks was centrifuged to remove carbonate and diluted with $\mathrm{CO}_{2}$ free distilled water. The extinction measurements were made in the $2 \mathrm{~mm}$. observation tube of the kinetic apparatus, with light of wavelength $435 \mathrm{~m} \mu$., the absorption maximum of acid bromophenol blue. The calibration fluids were $0.1 \mathrm{~N}$ $\mathrm{HCl}$ and Clarke and Lubs $\mathrm{KH}_{2} \mathrm{PO}_{4}-\mathrm{NaOH}$ buffer of $\mathrm{pH} 7 \cdot 0$. With an indicator concentration of $0.005 \%(w / v)$ the extinction change from acid to alkaline indicator was 0.35 , and the precision of the measurements with the spectrophotometer at minimum sensitivity was better than $\pm 0.01 \mathrm{pH}$ unit near $\mathrm{p} K_{I n}$.

The plot of $\log \left(\Delta E_{100 \%}-\Delta E\right) / \Delta E$ against $\mathrm{pH}$ is shown in Fig. 4. Within the experimental error, the points fall on a straight line of slope 0.98 , giving $\mathrm{p} K_{I n}=3.97$ at an ionic strength of 0.05 ; Kolthoff \& Rosenblum (1937) considered 4.00 to be the best value at this ionic strength.

Kinetic measurements. The reactants were $0.02 \mathrm{M}-\mathrm{NaHCO}_{3}$ and $0.01 \mathrm{~N}-\mathrm{HCl}$ solutions, each of which contained $0.005 \%$ bromphenol blue, and also served as calibration fluids. At each point of observation, the spectrophotometer was set to zero extinction with the $\mathrm{NaHCO}_{3}$ reagent in the observation tube, and measurements of $\Delta E_{100} \%$ and $\Delta E_{t}$. were made on the $\mathrm{HCl}$ reactant and the reaction mixture respectively. (Since only $99.2 \%$ of the indicator is in the acid form in the $\mathrm{HCl}$ reactant, a correction of $0.8 \%$ was added to the $\Delta E_{100} \%$ readings.) In most experiments, kinetic measurements were made at 8 or 10 points along the observation tube, 4 or 5 at increasing distances from the mixing chamber, and the remainder at intermediate points at decreasing distances from the mixing chamber, in order to compensate for small drifts of reactant temperature.

In the $\mathrm{pH}$ range of these experiments, the hydration reaction may be disregarded, and the mechanism

$$
\mathrm{d}\left[\mathrm{CO}_{2}\right] / \mathrm{d} t=k_{1}\left[\mathrm{H}_{2} \mathrm{CO}_{3}\right]
$$


leads to the relation (Brinkman et al. 1933):

$$
\begin{aligned}
& k_{1}\left(t_{2}-t_{1}\right)=\left\{1+\frac{K_{\mathrm{H}_{2} \mathrm{OO}_{3}}}{b-a}\right\} \ln \frac{\left[\mathrm{H}^{+}\right]_{1}}{\left[\mathrm{H}^{+}\right]_{2}} \\
& +\left\{1-\frac{K_{\mathrm{H}_{2} \mathrm{CO}_{3}}}{b-a}\right\} \ln \frac{\left[\mathrm{H}^{+}\right]_{1}+b-a}{\left[\mathrm{H}^{+}\right]_{2}+b-a},
\end{aligned}
$$

where $a$ =initial $\mathrm{HCl}$ concentration, $b=$ initial $\mathrm{NaHCO}_{8}$ concentration, $K_{\mathrm{H}_{2} \mathrm{CO}_{3}}=\left[\mathrm{H}^{+}\right]\left[\mathrm{HCO}_{3}^{\prime}\right] /\left[\mathrm{H}_{2} \mathrm{CO}_{3}\right]$. Since the jets delivered at about equal rates, $a=0.005$ and $b=0.01$.

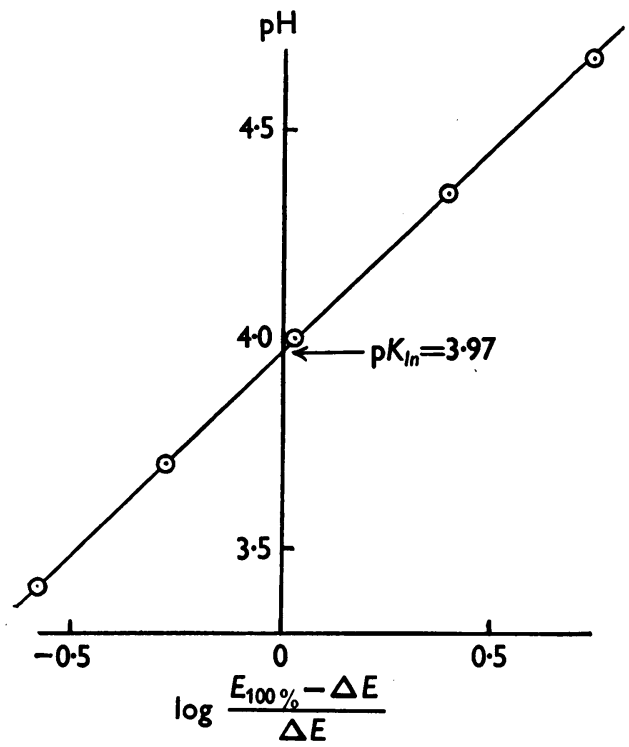

Fig. 4. Calibration curve for spectrophotometric determination of $\mathrm{pH}$ with bromophenol blue: plot of $\mathrm{pH}$ against $\log \frac{\text { [alkaline indicator] }}{\text { [acid indicator] }}$ for standard buffer solutions.

Taking $K_{\mathrm{H}_{2} \mathrm{CO}_{3}}=3 \times 10^{-4}$ at $18^{\circ}$ (Roughton, 1941) gives $K_{\mathrm{H}_{2} \mathrm{CO}_{8}} / b-a=0 \cdot 06$, and since the ionic strength changes little during the reaction, the above equation approximates very closely to

$$
k_{1}=2.30 \times 1.09 \frac{\mathrm{pH}_{2}-\mathrm{pH}_{1}}{t_{2}-t_{1}} .
$$

\section{RESULTS}

In Fig. 5, the time course of the pH is shown, as a plot of $\left(\mathrm{pH}-\mathrm{p} K_{I n}\right)$ against time, for four successive experiments with a $0.5 \mathrm{~mm}$. jet unit at a flow rate of $4.8 \mathrm{ml}$./sec. The points fall very closely on straight lines from which only the earliest measurements at a distance of $1 \mathrm{~cm}$. from the mixing chamber deviate by more than the calculated precision of the measurements. The close agreement between pairs of experiments at the same temper. ature shows that the results are independent of the slit length from 0.5 to $5 \mathrm{~mm}$.

The effect of flow rate is shown in Fig. 6, which gives the results of four experiments with a $1 \mathrm{~mm}$. jet unit at the same temperature of $18 \cdot 8 \pm 0 \cdot 1^{\circ}$. The

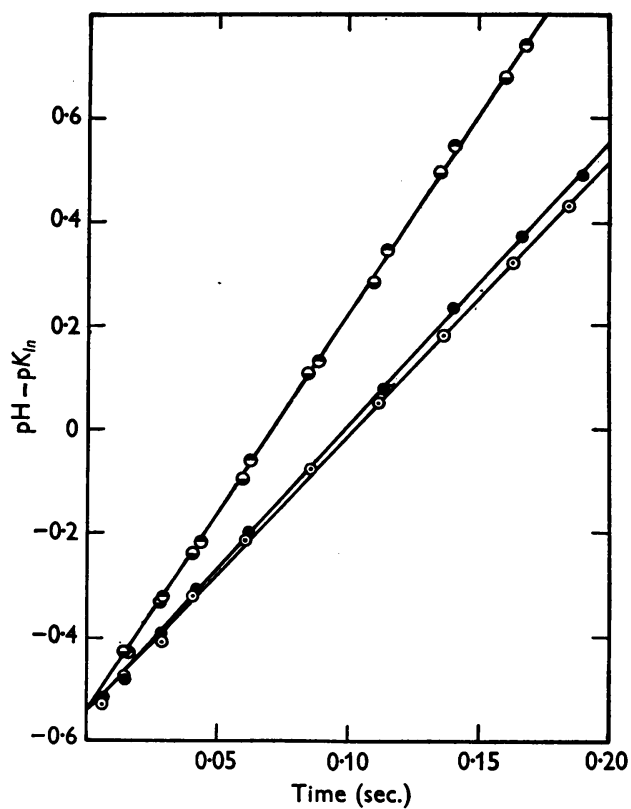

Fig. 5. Time course of $\mathrm{pH}$ after mixing $\mathrm{NaHCO}_{3}$ and $\mathrm{HCl}$ : ○, Exp. 1, 18.9 ${ }^{\circ}$, slit length $0.5 \mathrm{~mm}$; $\bigcirc$ Expt. 2, $19 \cdot 1^{\circ}$, slit length $2 \mathrm{~mm}$.; $\ominus$, Expt. 3, 22.9 ${ }^{\circ}$, slit length $5 \mathrm{~mm}$.; $\ominus$, Expt. 4, 22.8 ${ }^{\circ}$, slit length $0.5 \mathrm{~mm}$.

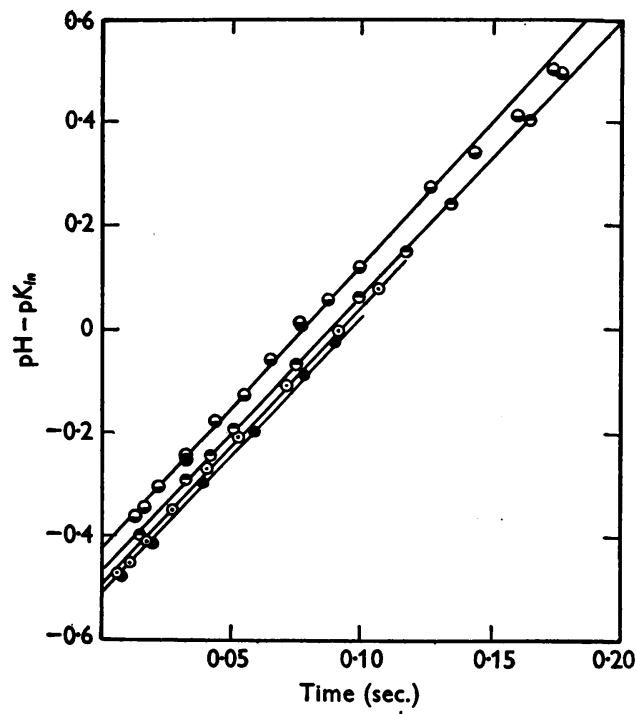

Fig. 6. Effect of flow rate on kinetic measurements:

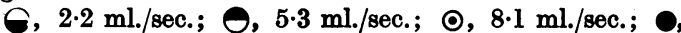
$10 \cdot 1 \mathrm{ml} . / \mathrm{sec}$.

flow rates were $2 \cdot 2,5 \cdot 3,8 \cdot 1$ and $10 \cdot 1 \mathrm{ml} . / \mathrm{sec}$. , and the critical flow rate for turbulence in the $2 \mathrm{~mm}$. bore observation tube was $3.5 \mathrm{ml}$./sec. The differences between the intercepts on the ordinate are due to small differences between the relative rates of delivery. The slopes of the best straight lines agree 
to within $\pm 2 \%$, but in the experiment at $2 \cdot 2 \mathrm{ml}$./ sec. there are significant deviations from linearity in the late stages of the reaction. The deviations are in the sense anticipated theoretically for streamline flow, but are of very much smaller magnitude than the calculated errors. Thus, over the first half of the reaction, the calculated errors (Table 2) are equivalent to no more than $0.02 \mathrm{pH}$ units, but when reaction reaches $87.5 \%$ of completion $(\mathrm{pH}-$ $\left.\mathrm{p} K_{I n}=0.5\right)$ the calculated error of $-4.8 \%$ amounts to $-0 \cdot 15 \mathrm{pH}$ units.

For fifteen experiments at temperatures in the range $18 \cdot 8-22 \cdot 9^{\circ}$, values of $k_{1}$ were calculated from the slopes by equation (4), and the plot of $\log k_{1}$ versus the reciprocal of the absolute temperature is shown in Fig. 7, which illustrates the precision of the method. The radius of the circles is equivalent to $1 \% k_{1}$ and $0 \cdot 1^{\circ}$. The greatest deviation from the best straight line amounts to $3 \% k_{1}$. Extrapolation gives $k_{1}$ at $18^{\circ}$ as $12.3 \mathrm{sec} .^{-1}$, and the energy of activation for the reaction calculated from the slope is $16900 \mathrm{cal} . / \mathrm{mole}$.

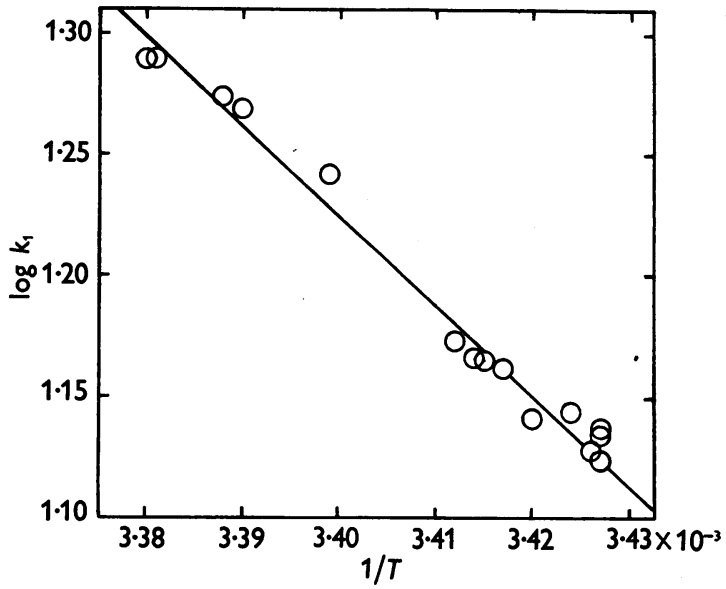

Fig. 7. Effect of temperature on the rate of dehydration of carbonic acid: plot of the logarithm of the velocity constant against the reciprocal of the absolute temperature. The radius of the circles is equivalent to $1 \% k_{1}$ and $0 \cdot 1^{\circ}$.

\section{DISCUSSION}

For the study of rapid reactions in general, the constant-flow method seems to be potentially more accurate than the accelerated-flow method. Chance's powerful technique was developed especially for the study of enzyme reactions, in which the technical difficulties are greatly augmented by the limited amounts of material available, and often by the smallness of the extinction coefficients of the reactants. For reactions free from these restrictions, the constant-flow method has the advantage of simplicity and of more direct and independent measurements of time and concentration, valuable assets when known and controlled precision is sought.

Of the two types of fluid drive which have been used in the constant-flow method, the original gaspressure drive and Millikan's motor-syringe drive, the former was chosen as likely to give the more constant flow rate, and also to preclude the possibility of electrical and mechanical interference with the spectrophotometer. The flow rate is constant in the present apparatus to better than $\pm 1 \%$ compared with $\pm 3 \%$ reported by Millikan $(1932,1936)$. The fluid requirements are of course considerably greater than in Millikan's method; 11 . of each reactant and $500 \mathrm{ml}$. of each calibration fluid will give a kinetic curve of 16 points for a reaction of half-period 0.03 sec. These requirements can be halved, with some sacrifice of precision, by modifications of procedure, such as calculation of the flow rate from the pressure and calibration of the observation tube so that only one measurement need be made on the fully reacted calibration fluid.
The principal new feature of the work is the application of accurate spectrophotometric analysis to the constant-flow method by means of a common type of spectrophotometer, with considerable gains in precision and in the range of application of the method. Since square tubes of uniform crosssection are difficult to obtain, and in any case would raise new problems of flow, it was necessary to establish the conditions under which valid measurements of extinction could be made in a cylindrical vessel, in order that Beer's Law could be applied and calibration curves avoided. It is perhaps worth mentioning that the conclusions reached have application to the common test-tube colorimeter. With a Beckman DU spectrophotometer, changes of reactant concentration of less than $1 \%$ can be recorded over the first $70 \%$ of a reaction, under suitable conditions. With a glass observation tube, any wavelength in the region $350-1000 \mathrm{~m} \mu$. is available, and the initial reactant concentrations can therefore be varied considerably without loss of precision; kinetic studies of a reaction at several wavelengths may reveal complexities, and the absorption spectra of transient intermediate compounds can be measured quantitatively (Dalziel \& O'Brien, 1952a).

The limiting error of the method at present is caused by rapid oscillation of the relative rates of delivery through the jets, manifest as an unsteadiness of the galvanometer needle which limits the precision of the concentration measurements, and prevents full advantage being taken of the sensitivity of the spectrophotometer. Such flow in- 
stability is probably inherent in a system of two directly impinging jets with a non-rigid fluid drive. The magnitude of the fluctuations does not change with the flow rate, but increases with the diameter of the jets. The fluctuations with $1 \mathrm{~mm}$. jets were reduced considerably by putting a short length of capillary at the entrance to the leads to the jets. The improvement is due, in part at least, to the fact that higher pressures are then required for a given rate of flow. The available range of flow rates, which is determined by the onset of cavitation in the jets, is greater with this arrangement than with $0.5 \mathrm{~mm}$. jets. It is possible that tangentially opposed jets would give a more stable flow.

The lower limit of the time range of the apparatus in the form described is at most 0.005 sec., the time required for $99 \%$ mixing with $1 \mathrm{~mm}$. jets at the highest rate of flow tested, namely $280 \mathrm{~cm}$. $/ \mathrm{sec}$. in a $2 \mathrm{~mm}$. bore observation tube with a driving pressure of $20 \mathrm{lb} . / \mathrm{sq} . \mathrm{in}$. With $40 \mathrm{lb}$./sq.in., a flow velocity of $400 \mathrm{~cm}$. $/$ sec. is obtained, and mixing might be still more rapid. More efficient multijet mixers might be used, as in earlier types (Roughton \& Millikan, 1936). The interaction of the various factors which determine the efficiency and range of the method have been discussed by Millikan (1936) and by Chance (1940).

The conclusions drawn from control experiments and calculations regarding the precision and validity of the method are supported by experimental work on the dehydration of carbonic acid. Measurements at several rates of flow conformed closely to the requirements of the accepted mechanism, and estimates of the velocity constant were reproducible to $\pm 3 \%$. The mean value of $k_{1}=12.3 \mathrm{sec}^{-1}$ at $18^{\circ}$ is in satisfactory agreement with those of most previous workers, listed by Roughton (1936, 1941), and the figure of $16900 \mathrm{cal} . / \mathrm{mole}$ for the activation energy agrees well with the value of $16500 \mathrm{cal}$./ mole obtained by Roughton (1941) with a thermal method. With the indicator method used in the present work, Brinkman et al. (1933) found $k_{1}=12.8$ sec. $^{-1}$ at $18^{\circ}$ as the mean of two results differing by $10 \%$; using the data of a third, unpublished, experiment Roughton (1941) corrected this figure to 13.6 sec. ${ }^{-1}$. With the thermal method, however, Roughton (1941) obtained $k_{1}=14 \cdot 6 \pm 0 \cdot 7$, which he considers to be the most reliable value. There is a possibility that the indicator method may be unsuitable for rapid reactions involving carbon dioxide (Roughton, 1952).

Further evidence for the precision of the technique was obtained in studies of the deoxygenation of human haemoglobin (Dalziel \& O'Brien, 1950) with an earlier version of the apparatus. The difference between duplicate measurements at the same distance along the tube in a large number of experiments very rarely exceeded the estimated error of time and concentration measurements, and in a set of four experiments with the same sample of blood under identical conditions the variation in the velocity constant for the last $70 \%$ of the reaction was $\pm 2 \%$. An upward trend of the velocity constant during the first $30 \%$ of the deoxygenation, predicted by the intermediate compound theory (Roughton, 1949) and recently detected by Legge \& Roughton (1950), was confirmed in these experiments at wavelengths of 415, 430465 and $560 \mathrm{~m} \mu$., and lies well outside the error of analysis. It is hoped that the technique will yield kinetic data accurate enough to contribute to the experimental evaluation of the intermediate compound theory outlined by Roughton (1949) and developed in recent accurate equilibrium studies (Paul \& Roughton, 1951 ; Lyster, Otis \& Roughton, 1951).

\section{SUMMARY}

1. A form of Hartridge-Roughton rapid reaction apparatus has been developed with precision as the major objective of the design. The apparatus consists of a constant-flow apparatus with gas-pressure drive and a photoelectric spectrophotometer with which the extent of a reaction or the spectral absorption of transient compounds may be measured.

2. The conditions under which Beer's law may be assumed valid for extinction measurements in a cylindrical tube have been determined, and the factors governing the choice of wavelength for accurate kinetic measurements are stated. The extent of a suitable reaction can be estimated to within $\pm 1.5 \%$ or less over the first three-quarters of its course, the limiting error arising from the instability of the relative rates of delivery of the reactants through the jets.

3. It is shown theoretically that with turbulent flow in the observation tube the validity and precision of the method should not be affected significantly by the deviations from ideal flow. The precision of the time measurements, determined by the constancy of the total flow rate, is $\pm 1 \%$.

4. At the highest flow rate tested, $280 \mathrm{~cm}$. $/ \mathrm{sec}$. in the $2 \mathrm{~mm}$. bore observation tube with a driving pressure of $20 \mathrm{lb}$./sq.in., mixing occurs to the extent of $99 \%$ in 0.005 sec.

5. A value of $12 \cdot 3 \pm 0.4 \mathrm{sec}^{-1}$ at $18^{\circ}$ was obtained for the specific reaction rate of

$$
\mathrm{H}_{2} \mathrm{CO}_{3} \rightarrow \mathrm{CO}_{2}+\mathrm{H}_{2} \mathrm{O}
$$

by spectrophotometric measurements of the rate of change of $\mathrm{pH}$ in acid-bicarbonate mixtures. The effect of temperature on the velocity constant in the range $19-23^{\circ}$ gave the energy of activation as $16900 \mathrm{cal} . / \mathrm{mole}$. The $\mathrm{p} K_{\text {In }}$ value for bromophenol blue was found to be 3.97 at an ionic strength of 0.05 . 
I wish to thank Mr J. R. P. O'Brien, at whose suggestion this work was undertaken, for advice and criticism. I am very greatly indebted to $\mathrm{Mr}$ J. T. Cox, who constructed the apparatus and contributed much to the design, and to Mr H. Vincent, who rendered similar services in connexion with the glass components. I am grateful also to $\mathrm{Mr}$ B. A. Collett for technical assistance during part of the work, to Mr R. S. Salt for help with the gas-pressure system and to Dr G. H. Epstein for helpful discussions of flow problems.

\title{
REFERENCES
}

Bateman, J. B. \& Roughton, F. J. W. (1935). Biochem. J. 29, 2622.

Brinkman, R., Margaria, R. \& Roughton, F. J. W. (1933). Phil. Trans. 232, 65.

Brode, W. (1924). J. Amer. chem. Soc. 46, 581.

Chance, B. (1940). J. Franklin Inst. 229, 455, 613, 737.

Chance, B. (1951). Rev. sci. Instrum. 22, 619.

Dalziel, K. \& O'Brien, J. R. P. (1950). Unpublished.

Dalziel, K. \& O'Brien, J. R. P. (1951). Biochem. J.49, xlvii. Dalziel, K. \& O'Brien, J. R. P. (1952a). Biochem. J. 52, v. Dalziel, K. \& O'Brien, J. R. P. (1952b). Biochem. J. 52, vi.

Dodge, R. A. \& Thompson, M. J. (1937). Fluid Mechanics, 1st ed. p. 211. New York: McGraw-Hill.

Drabkin, D. L. \& Austin, J. H. (1935-6). J. biol. Chem. 112, 105.

Faurholt, C. (1924). J. Chim. phys. 21, 400.

Hartridge, H. \& Roughton, F. J. W. (1923). Proc. Roy. Soc. A, 104, 395.

Hartridge, H. \& Roughton, F. J. W. (1924). Proc. Camb. phil. Soc. 22, 426.
Kolthoff, I. M. \& Rosenblum, C. (1937). Acid-Base Indicators, p. 293, lst ed. New York: Macmillan.

Legge, J. W. \& Roughton, F. J. W. (1950). Biochem. J. 47, 43.

Lyster, R. L. J., Otis, A. B. \& Roughton, F. J. W. (1951). J. Physiol. 115, $16 P$.

Millikan, G. A. (1932). Ph.D. Thesis, Cambridge.

Millikan, G. A. (1936). Proc. Roy. Soc. A, 155, 277.

Paul, W. \& Roughton, F. J. W. (1951). J. Physiol. 113, 23.

Roughton, F. J. W. (1930). Proc. Roy. Soc. A, 126, 439.

Roughton, F. J. W. (1936). Proc. Roy. Soc. A, 155, 269.

Roughton, F. J. W. (1941). J. Amer. chem. Soc. 63, 2930.

Roughton, F. J. W. (1949). Haemoglobin, p. 83. London: Butterworth's Scientific Publications.

Roughton, F. J. W. (1952). Personal Communication.

Roughton, F. J. W. \& Millikan, G. A. (1936). Proc. Roy. Soc. A, 155, 260.

Vogel, A. I. (1939). Quantitative Inorganic Analysis, lst ed. London: Longmans Green and Co.

\section{APPENDIX}

\section{The Precision of Analysis by Photoelectric Spectrophotometry}

\author{
BY K. DALZIEL \\ Department of Biochemistry, Radcliffe Infirmary, Oxford
}

Twyman \& Lothian (1933) showed that the percentage error of photoelectric measurements of extinction, $E$, is at a minimum for $E=0.43$. If $\delta \theta=$ smallest detectable galvanometer deflexion, $T=$ transmission $=I_{t} / I_{o}$ and $\delta T=$ smallest measurable transmission change, then $\delta T=k \delta \theta$, where $k$ is constant for a given voltage drop across the potentiometer. Since

$$
E=\log 1 / T, \quad \mathrm{~d} E=-\mathrm{d} T / 2 \cdot 3 T=-\mathrm{d} T 10^{x} / 2 \cdot 3,
$$

and hence, if $\delta T$ is small, the smallest measurable extinction change is

$$
\delta E=-\frac{10^{x}}{2 \cdot 3} \delta T .
$$

The precision of extinction measurements therefore decreases with increase of extinction. The proportional error of extinction measurements is given by

$$
p=\frac{\delta E}{E}=-\frac{10^{E}}{2 \cdot 3 E} \delta T,
$$

and is a minimum when $E=0 \cdot 43$.
With the Beckman spectrophotometer at minimum potentiometer sensitivity, we find

$$
\delta T=2 \times 10^{-3} .
$$

The corresponding absolute and proportional errors of extinction measurements, calculated from equations (1) and (2), respectively, are plotted against extinction in Fig. 1 : if Beer's law is obeyed, these curves show the errors in concentration measurements. At maximum sensitivity, $\delta T=10^{-3}$, and the errors are half as great.

If a spectrophotometer be set to read $E=0$ with an absorbing solution $A$, the reading with a second solution $B$ is the extinction difference, $\Delta E=E_{B}-E_{A}$. Equations (1) and (2) will apply if $\Delta E$ is substituted for $E$, and it follows that, for a given value of $\delta T$, a more precise estimation of $\Delta E$ will be obtained in this way than by measuring $E_{A}$ and $E_{B}$ separately. This principle can be used, for example, to determine accurately the ratio of the optical depths of two cells. 